\title{
Economic Cost of Road Traffic Accidents in Twin Cities, Pakistan
}

\author{
Komal Chaudhry (MS) \\ Muhammad Jawed Iqbal (PhD) \\ Department of Transportation Engineering, \\ School of Civil and Environmental Engineering, \\ National University of Science and Technology, Pakistan
}

Doi:10.19044/esj.2018.v14n25p142 URL:http://dx.doi.org/10.19044/esj.2018.v14n25p142

\begin{abstract}
Road Traffic Accidents in developing countries are a serious concern in terms of safety and economy. RTAs share a considerable amount of overall life, resource, and productivity losses. It has become essential to monetize RTAs to aid the policymakers, economists, and the state government to efficiently select the cost-effective countermeasure for the safety of road users. The costs can be utilized in framing cost-effective safety measures and policies. This paper focuses on estimating the overall costs of Road Traffic Accidents in the city of Rawalpindi/Islamabad, Pakistan, by using the Human Capital Approach to estimate the monetary amount that the Road Traffic Accidents have cost to the cities in the year 2016. The research has categorized the costs into 5 main components, namely: medical costs, property damage costs, loss output, human loss, and administrative costs. A total of 10187 incidents have been recorded in the cities involving 12573 victims and 18136 vehicles. Results suggested that a total of pkr 2.183 billion has been incurred by the State of Pakistan with a loss of about $0.0074 \%$ to the GDP. The breakdown of the costs was as follows: Medical costs (pkr 93,898,640), and it comprises $4.26 \%$ of the total cost; Property damage costs include vehicular and property damage repair (pkr 214,840,463), and it comprises $9.84 \%$ of the total cost; Loss output (pkr 1,316,000,000), and it comprises $60.27 \%$ of the total cost; Human costs (pkr 473,584,345), and it comprise $21.69 \%$ of the total cost; Administrative costs (pkr 85,730,725), and it comprises $3.92 \%$ of the total cost.
\end{abstract}

Keywords: Road Traffic Accidents, Economic Cost, Human Capital Approach, Pakistan 


\section{Introduction}

Road Traffic Accidents at present is one of the leading contributors to the world's mortalities and disabilities. The road accidents are one of the most critical problems being faced by people, countries, government etc. Apart from the humanitarian aspect of reducing road deaths and injuries in developing countries, a strong case can be made for reducing road crash deaths on economic grounds alone, as they consume massive financial resources that the countries can ill afford to lose. Road Traffic Accidents in developing countries are a serious concern in terms of safety and economy. The costs of RTAs are divided into two, namely direct and indirect costs, which include the medical costs, administrative costs, property and vehicle damages, etc. Therefore, this paper focuses on estimating the overall costs of Road Traffic Accidents in the city of Rawalpindi/Islamabad, Pakistan, by using the Human Capital Approach to estimate the monetary amount that the Road Traffic Accidents have cost to the cities.

RTAs are said to be the leading cause of death and hence human productivity loss worldwide. In Viet Nam, the death rate due to RTAs was 27 per 100,000 persons in 2002 , whereas the average death rate worldwide was 19 per 100,000 . A total of 20774 traffic accidents were reported in the year 2003 which had resulted in 12,864 mortalities and 20,704 injuries. Contrarily, the strong traffic safety interventions and measures, taken by the French government in 2002, had resulted in a $20 \%$ reduction in fatality in a year. A total of 7242 deaths had occurred from Traffic accidents in the year 2002; thus, the number had reduced to 5732 in 2003 (WHO, 2004). World health organization states that approximately 3500 lives are lost every day due to RTIs, with about 1.27 million deaths each year, globally. An additional 20 - 50 million people sustain non-fatal RTIs and are contributing to disability worldwide. Statistics revealed that almost $70 \%$ of Road Traffic Accidents occur in the developing countries (A J Downing et al., 1991).

According to the World Bank, road accidents cost a country about 2\% of its national income. More than 90 percent of the world's road fatalities occur in developing countries, and half of the accident victims are pedestrians, cyclists, and motorcyclists. Road traffic deaths are predicted to decline by $30 \%$ in high-income countries (HICs). Nonetheless, a substantial increase is expected in low and middle-income countries. RTIs will be the third leading contributor to the global burden of disease by 2020 if immediate and effective actions are not taken now. A total of $1-3 \%$ of gross national product (GNP) has been lost globally, particularly from LMICs, approximating to $\$ 500$ billion in total. Such accidents share a considerable amount of overall life, resource, monetary, and productivity losses. World Bank projections indicate that global road fatalities will increase by more than 65 percent between the years 2000 and 2020, unless intensified safety interventions are implemented, with this 
trend varying across the various regions of the world. Fatalities are predicted to increase by more than 80 percent in low and middle-income countries, but decrease by nearly 30 percent in high-income countries (Kopits \& Cropper, 2005). The economy of any country is highly dependent upon the productive age group (15 years - 44 years); which sadly in Pakistan, they are exposed to major threats demanding their health and lives.

\section{Literature Review}

An increase in GDP in developed countries reduces the casualty rate of traffic accidents, but it has no effect on a number of crashes or injuries. In lowincome countries, which had GDP to per capita ratio lesser than 1600, an increase in a number of road crashes by $7.9 \%$, the number of road traffic by $4.7 \%$, and a number of deaths by $3.1 \%$ is expected as a result of a $10 \%$ increase in GDP. The authors suggest that the invariable increase in a number of traffic injuries, crashes, and deaths is independent of roadway availability, vehicle counts, population size, and fuel. It was concluded that the number of casualties no longer depends on economic growth at a certain threshold of \$1500-\$8000 per capita income (David Bishai et al., 2006).

A vast research was carried out which studied the effect of income on fatalities per vehicle, motorization rate, and death rate by road traffic injuries using data from 88 countries for the years 1963-1999. While introducing separate models for fatalities/vehicles, fatalities/population, and vehicle/population, they projected their data to the year 2020. The projected results suggested that the death rate from road traffic accidents would grow by $66 \%$ in the years 2000-2020. However, the divergent range was observed in the results - a decrease in death rate by approximately $28 \%$ was observed for high-income countries, an increase of almost $147 \%$ was observed for India, and $92 \%$ for China. The authors also predicted that the death rate in low and middle-income countries shall rise to 2 per 10000 , while in developed countries, it was estimated to fall to less than 1 per 10000 by the year 2020 . Similarly, in Kenya and Nigeria, a fivefold raise was observed over the last 30 years in traffic-related casualties (Kopits \& Cropper, 2005).

It was observed that the economies of developing countries are affected at a rate of approximately 1-2\% of their GNP (WHO, 1989; Jacobs \& Sayer, 1983). RTAs were calculated to cost $2.56 \%$ of the total GDP of Thailand in the year 2002 (Luathep \& Tanaboriboon, 2005). In India, in the year 2004, a crash rate of $16.2 \%$ per 100,000 was recorded. The study was divided into net costs which included all the medical costs and vehicle costs, which cost about $\$ 19,991$; in addition, productivity costs were the result of premature mortality lost (Reddy et al., 2009). Similarly, RTAs have cost Australia 2.28\% of her total GDP (Connelly \& Supangan, 2006). 
The literature has revealed that many types of researches include similar components, i.e. loss output, medical losses, familial losses, property damage losses, and loss in the quality of life. In Jordan, in the year 1996, similar components were considered and they added up to an amount of 103 million Jordanian dollars (Al-Masaeid et al., 1999). However, the factor of quality of life was not noticed in many studies. Rune Elvik, in a study, proposed that researchers must evaluate the lost quality of life in their studies since excluding the lost quality of life drops the overall cost of traffic accidents from $3.1 \%$ of GNP to $1.4 \%$ of GNP (Elvik, 2000). In Metro Manila, the costs were divided into victim related, property damage, and administration costs. The analysis showed that $\mathrm{PhP} 2,532,250$ was costed per fatal accident, out of which $73 \%$ were mainly because of lost income and disabilities (De Leon et al., 2005).

\section{Methodology}

Out of six methods defined by the overseas Road note 10, only 2 are appropriate to cost the road traffic accidents, Human Capital (Gross output), and Willingness to Pay. This study tends to adopt the Human capital or gross output approach to calculate the cost of road traffic accidents in Pakistan since it deals with the direct and indirect costs involved in the RTAs (Prasanta K. Sahu, 2012). The Human Capital Approach/ Gross Output Approach is based on identifying and determining the individual factors which are involved in a road traffic accident, and which causes a loss to the economy, either directly or indirectly, and adding them up to a concrete value. The method includes the monetized value of pain, grief, and suffering caused by the loss of human lives. The research tends to find out the cost of road traffic crashes which occurred in the twin cities, Rawalpindi and Islamabad, Pakistan, in the year 2016. In carrying out this study, the factors of the overall accident cost were divided into subcategories, each of which is determined individually, as shown in the figure below (Figure 3.1): 


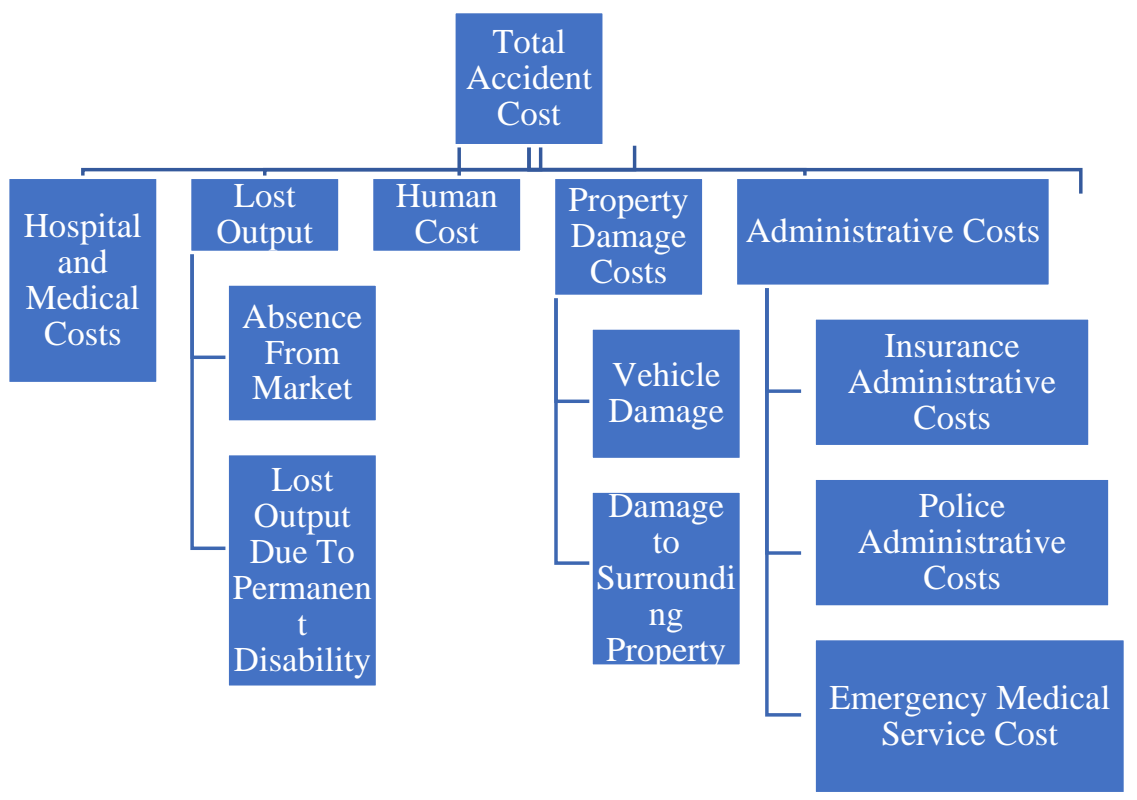

Figure 3.1. Subcategorization of Costs

To calculate the separate costs of each individual factor mentioned in Figure 3.1, the following preliminary data are required: Total Number of Accidents in the year 2016; total number of victims involved in the accidents; victims biodata involving age, gender, education and income; type of injury; the hospital the victim was carried to; the rehabilitation time that the victim required; type of vehicle involved in the accident; the cause of the crash; and the area in which the crash occurred. The data acquisition involved the following sources: rescue emergency services, hospitals, police department, insurance companies, highway authorities, and vehicle repair workshops.

\subsection{Medical Costs}

The overall costs incurred for the complete treatment of the victim is referred to as medical costs. Subsequently, the study has divided all the medical centers recorded into 3 parts depending on their extent of charges: High-income, middle-income, and low-income hospitals. The charges for each injury were determined by taking the average of two hospitals visited in each category. If the injury is trivial enough to be dealt with by the physicians/paramedics staff provided by the emergency service, the treatments are then provided by the emergency service itself. Such treatments were referred to as an on-spot treatment. The cost of each injury is to be determined by hospital visits, interviews of hospitals' staff and physicians, and the interview of paramedics staff of emergency medical services. medical

Therefore, the following formula was used in the research to find the costs: 
[Number of $A(D A L Y)$ Injuries $*$ unit cost/injury $)+($ in-patient period $*$ hospital cost/injury/day)] + [Number of A injuries * \{unit cost/injury + (in-patient period $*$ hospital cost/injury/day) $\}]+[$ Number of B injuries $*\{$ unit cost/injury $+($ in-patient period $*$ hospital cost/injury/day $)\}]+[$ Number of $C$ injuries $*$ $\{$ unit cost/injury $+($ in-patient period $*$ hospital cost/injury/day $)\}]+[$ Number of $K$ injuries $*$ \{unit cost/injury + (in-patient period $*$ hospital cost/injury/day)\}]

$\mathrm{KABCO}$ scale has been used in the study to identify injuries. KABCO is an injury classification system, in which injury codes are assigned to each injury type. The code K refers to fatality, A to incapacitating injury, B to noncapacitating injury, $\mathrm{C}$ to possible injury, and $\mathrm{O}$ to property damage only. In order to include the damage caused by the prolonged disability due to spinal cord injuries, the injury A has been further subdivided into A(DALY) i.e. injury A inclusive of disability-adjusted life years. This injury scale that was created made it convenient for the study to deal with the various spinal cords injuries separately. The victim's injuries were analyzed before assigning the injury code to them.

\subsection{Lost Output}

The lost output is referred to as the "loss of productivity" of any person who has been injured by a road traffic accident. It is basically the total monetized productivity of the victim had he not been injured and he is continuing with his work routine. The amount of lost output varies in each case, depending upon the age and income of the victim as well as the severity of the crash. The two main factors required for estimation of lost output are the average wages of the victims and the amount of time lost of the patient during the treatment and rehabilitation of injuries caused due to the road accident. This study includes two main factors to get the total lost output: Absence from Market and lost output due to disability. Absence from market includes the temporary absence resulted from the injury where the Road Crash Victim were unable to perform his duty in his workplace while in rehabilitation period. Thus, it is calculated as: The market lost output due to the absence of the victim from the workplace $=($ wage of victim $*$ Rehabilitation period $)$. Here, "Rehabilitation Period" is the time period during which the victim is treated and healed to the extent that he is able to return back to his workplace again. The rehabilitation period in this study has been classified for each injury type i.e. A, B, and C. Since each victim faced a different type of injury caused by a different crash scenario, the study found it suitable to allocate different Rehabilitation periods for each case individually. The period was mainly idealized by physicians' interviews by providing them with a hypothetical situation and not disclosing the actual cases. Victims' wages were analyzed by their age and education. 
Loss output due to disability was found using the following formula: $A(D A L Y)=$ Years lost $*$ Wage/day $* 365$

Where Years lost $=$ Average Living Age - Age at which the victim face the accident.

$\Rightarrow$ Average Age $=66.38$. The case where the age of victim exceeded the average age was accordingly taken as nil.

\subsection{Human Loss}

To determine the cost of human life, a total number of human lives lost were determined. The lives lost here refers to the victims who had been reported dead in either of the cases: prior to the arrival of any Emergency Service (Public/Private), during the medical aid by the emergency service, while being carried to the hospital, and the arrival of the victim at the hospital but reported dead within 24 hours by the hospital administration and was also reported to the rescue/emergency medical service. The human cost was analyzed by lawyer surveys, and it legally includes the monetized value of human life and the pain, grief, and suffering. The term "pain, grief, and suffering" refers to the suffering of the victims themselves as well as their dependants. Each year, the state of Pakistan specifies an amount to monetize human life and the pain and suffering associated with it. In the year 2016, the State of Pakistan had entitled a sum of $800,000 \mathrm{pkr}$ for a dead victim's family members to cater for the pain and suffering as well as monetary loss of output of the deceased caused to the members. Thus, the following formula was used to monetize the human loss:

Monetized value of lost output for a total number of casualties $=$ Total number of casualties * cost of Human Life as enlisted by the State

\subsection{Property Damage Costs}

In a Road Traffic Crash, the types of collisions include the following cases: vehicle to a vehicle collision, vehicle to roadside furniture collision, and vehicle to victim collision. The first two types of collision mentioned are included in property damage i.e. the damage caused to the vehicles as well as the surrounding area, which might include any roadside object included in the right of way of the road. Vehicular damage includes the damage to vehicles caused by the collision in a Road Traffic Accident. The vehicular damage in this research is assessed individually by analyzing each accident case separately and getting to know the total number of vehicles involved, type of vehicles, and the extent of damage to the vehicle. Roadside furniture damage included the roadside objects which may include road barriers or curbstones, footpath, bridges, walls adjacent to roads, electric poles, security checkpoints, etc. The exact cost is determined by analyzing the cost which is needed to repair the damage caused to any type of property/roadside furniture. 


\subsection{Administrative Costs}

For each accident that occurs, along with all other material and property and lives and medical costs, there are other costs which are directly or indirectly involved in the accident. Such costs are mostly incurred by the government or autonomous philanthropist bodies. The research identifies such costs as administrative costs. Luathep and Tanaboriboon (2005) in their research, on the determination of economic costs of Road Traffic Accidents in Thailand, subdivided the costs into 3 components as shown in the chart below:

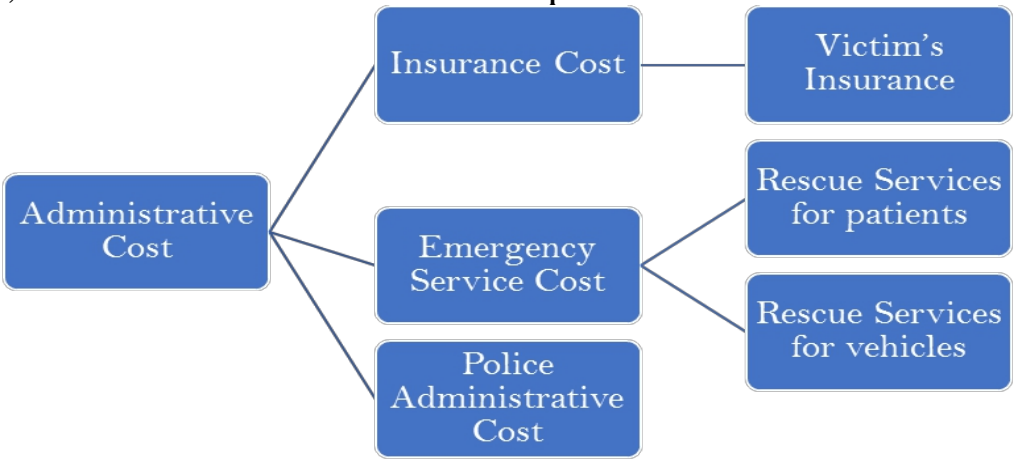

Figure 3.2. Administrative Costs

Insurance Costs include the victim's insurance by getting the data from the insurance policies. There are a few recorded insurance policy companies in the twin cities. The companies have registered different types of insurance policies with them. While a person/victim gets himself registered for the insurance policy, he/she makes a contract with the claim department of the company for any specific amount against any particular type of accident. The research has already considered the medical treatment in monetary terms. Hence, the insurance in terms of medical treatment is left unconsidered and only death claims are considered in the research.

Police Administrative Costs: Road Traffic Accident is considered a medico-legal case and hence the police department is always included in such cases. The administrative cost pertaining to the police department, although is very minute when compared to the rest, can be calculated by specifying the time the department invests in a single case. The time consumed by the police department is assumed to be the same for each severity of the accident. Since it is the duty of the department to follow up on such cases, the administrative cost is calculated by monetizing the time spent by the personals while investigating the case. The time is monetized by figuring out the monthly salary of the person and calculating it for the specified time invested in different case irrespective of the case severity.

Emergency Medical Service Cost: The medical service cost is assumed to be comprised of two parts; the time spent while handling cases and the fuel adjustment. The service is monetized by considering the time each service 
provider invests while dealing with the case. There are certain cases where the victim does not need to go to the hospital and can be treated with the first aid kit, present with the paramedic's staff of the medical service. The cost incurred by the rescue services can be found by monetizing the time of paramedic's staff and the driver of the emergency vehicle (ambulance) by figuring out the monthly salary of the person, calculating it for the specified time invested in different case, and multiplying the total number of cases with each severity level by the monetized cost. The cost of fuel utilized can be found by identifying the path of the vehicles, note the average mileage, and obtain the fuel utilized for the trips.

\section{Results and Discussions}

A total of 10187 RTAs had been recorded in the twin cities in Pakistan during the period of $1^{\text {st }}$ Jan 2016 to $31^{\text {st }}$ Dec 2016. These RTAs involved 12463 victims and 18,136 vehicles, with 38 PDO cases and 62 unknown. The victim's classification is as shown below:

Table 4.1. Gender of RTA Victims

\begin{tabular}{ccc}
\hline Gender & Frequency & Percent \\
\hline Females & 1730 & $13.88 \%$ \\
\hline Males & 10733 & $86.12 \%$ \\
\hline TOTAL & 12463 & $100 \%$ \\
\hline
\end{tabular}

Table 4.2. Age of RTA Victims

\begin{tabular}{ccc}
\hline Age Range & Number of Cases & Percent \\
\hline $\mathbf{1 - 1 4}$ & 567 & $4.55 \%$ \\
\hline $\mathbf{1 5 - 2 1}$ & 2956 & $23.72 \%$ \\
\hline $\mathbf{2 2 - 4 5}$ & 6549 & $52.56 \%$ \\
\hline $\mathbf{4 5 - 6 5}$ & 1747 & $14.02 \%$ \\
\hline$>65$ & 644 & $5.15 \%$ \\
\hline Total & 12463 & $100 \%$
\end{tabular}

A total number of injury recorded were classified as follows: $K: 1645, A: 3778, A(D A L Y)$ :

91, B: 6512, C: 437, O:38, U: 62 (where $O$ is property damage only and $U$ are the unknown RTA cases).

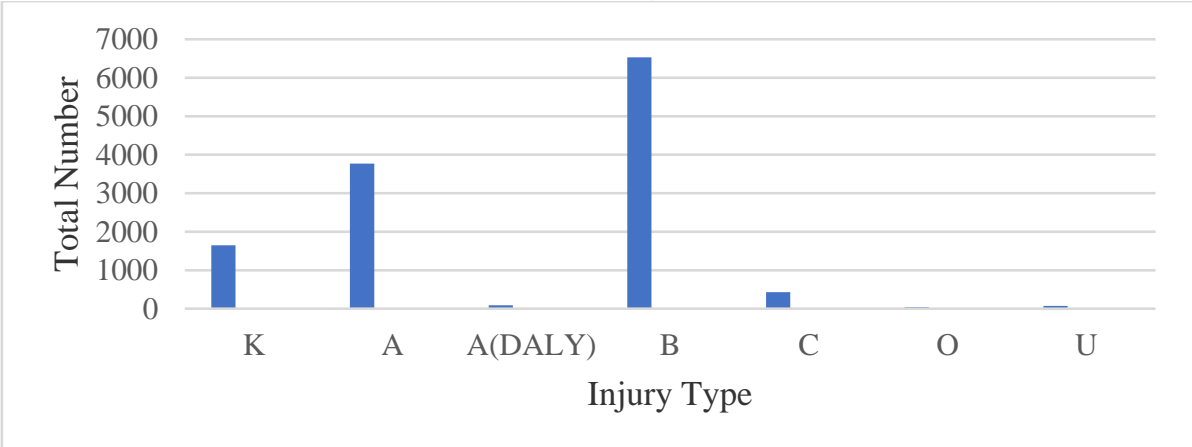

Figure 4.1. Total number of Injuries 
Unknown cases refer to the RTAs which were recorded in the database by emergency service, but the whereabouts of the patient and the details of the accident remain unknown.

\subsection{Medical Costs}

The tables below show the total injuries according to medical centers categorization:

Low-Income Medical Centres

Table 4.3. Medical Cost for Low Income Medical centers

\begin{tabular}{|c|c|c|c|}
\hline Injuries & $\begin{array}{c}\text { Number of } \\
\text { Cases }\end{array}$ & $\begin{array}{c}\text { Costs } \\
\text { Incurred }\end{array}$ & \% Weight of Costs \\
\hline Total Cases & 9067 & 64090925 & $100 \%$ \\
\hline A(DALY) & 82 & 20500000 & $31.9 \%$ \\
\hline A & 2842 & - & - \\
\hline $\begin{array}{c}\text { Out of which Severe } \\
\text { Bleeding/Bruises }\end{array}$ & 42 & 168000 & $0.262 \%$ \\
\hline Out of which Head Injury & 805 & 4830000 & $7.5 \%$ \\
\hline Out of which Single Fracture & 1910 & 28650000 & $44.7 \%$ \\
\hline Out of which Multiple Fracture & 85 & 3910000 & $6.1 \%$ \\
\hline $\mathbf{B}$ & 4439 & 4439000 & $6.9 \%$ \\
\hline $\mathbf{C}$ & 185 & 74925 & 0.117 \\
\hline $\mathbf{K}$ & 1519 & 1519000 & $2.5 \%$ \\
\hline
\end{tabular}

The cost was calculated to be pkr 64,090,925.

Middle-Income Medical Centres

Table 4.4. Medical Cost for Middle-Income Medical centers

\begin{tabular}{|c|c|c|c|}
\hline Injuries & $\begin{array}{c}\text { Number } \\
\text { of Cases }\end{array}$ & $\begin{array}{c}\text { Costs } \\
\text { Incurred }\end{array}$ & $\begin{array}{c}\text { \% Weight of } \\
\text { Cost }\end{array}$ \\
\hline Total Cases & 552 & $13,244,000$ & $100 \%$ \\
\hline A(DALY) & 7 & 3150000 & $23.7 \%$ \\
\hline A & 176 & 8270000 & 62.42 \\
\hline Out of which Severe Bleeding/Bruises & 9 & 99000 & $0.747 \%$ \\
\hline Out of which Head Injury & 47 & 1457000 & $11 \%$ \\
\hline Out of which Single Fracture & 114 & 6156000 & $46.48 \%$ \\
\hline Out of which Multiple Fracture & 6 & 558000 & $4.2 \%$ \\
\hline B & 272 & 1360000 & $10.2 \%$ \\
\hline C & 7 & 14000 & $0.1 \%$ \\
\hline K & 90 & 450000 & $3.39 \%$ \\
\hline
\end{tabular}

The cost was calculated to be pkr 13,244,000. 
High-Income Medical Centres

Table 4.5. Medical Cost for High Income Medical centers

\begin{tabular}{|c|c|c|c|}
\hline Injuries & $\begin{array}{c}\text { Number } \\
\text { of Cases }\end{array}$ & $\begin{array}{c}\text { Costs } \\
\text { Incurred }\end{array}$ & $\begin{array}{c}\text { \% Weight of } \\
\text { Cost }\end{array}$ \\
\hline Total Cases & 258 & 15187000 & $100 \%$ \\
\hline A(DALY) & 2 & $2,000,000$ & $13.16 \%$ \\
\hline A & 88 & - & - \\
\hline Out of which Severe Bleeding/Bruises & 14 & 308000 & $2 \%$ \\
\hline Out of which Head Injury & 19 & 1007000 & $6.63 \%$ \\
\hline Out of which Single Fracture & 51 & 8874000 & $58.43 \%$ \\
\hline Out of which Multiple Fracture & 4 & 1568000 & $10.3 \%$ \\
\hline B & 118 & 1180000 & $7.76 \%$ \\
\hline C & 14 & 70000 & $0.469 \%$ \\
\hline K & 36 & 180000 & $1.18 \%$ \\
\hline
\end{tabular}

The cost was calculated to be pkr 15,187,000.

On Spot Treatment

Table 4.6. Medical Cost for On Spot Treatment

\begin{tabular}{|c|c|c|c|}
\hline Injuries & Number of Cases & Costs Incurred & $\begin{array}{c}\text { \% Weight of } \\
\text { Cost }\end{array}$ \\
\hline Total Cases & 2586 & $1,376,715$ & $100 \%$ \\
\hline A & 672 & 672000 & $48.8 \%$ \\
\hline B & 1683 & 681615 & $49.5 \%$ \\
\hline C & 231 & 23100 & $1.67 \%$ \\
\hline
\end{tabular}

The cost was calculated to be pkr 1,376,715.

The overall medical cost incurred in the year 2016 in the twin cities was pkr 93,898,640. The unit medical cost derived for fatal accidents came out to be pkr 1306, for serious accidents pkr 10,834, and for minor accidents pkr 812.63.

4.2 Loss Output

Total lost output due to the absence of victim from the workplace is $\mathrm{pkr}$ $103,805,183$, whereas the total lost output due to permanent disability of victim is pkr $369,779,162$. Hence, total loss output is given as: pkr 1,316,000,000.

\subsection{Human Loss}

Human loss cost in this study is assumed as the monetized cost for covering the loss of human life and pain and suffering of the loved ones of the victim. Hence, the cost itself is a cost for all the fatal accidents. In addition, the total Human Cost came out to be pkr 1,316,000,000.

\subsection{Property Damage Only}

The breakdown of the types of vehicles involved in crashes/RTAs is as follows: 
Table 4.7. Vehicular Data

\begin{tabular}{|c|c|}
\hline Type of Vehicle & Frequency \\
\hline Bicycles & 74 \\
\hline Motor Bikes & 8880 \\
\hline Buses & 145 \\
\hline Cars & 5224 \\
\hline Vans & 2339 \\
\hline Trucks & 564 \\
\hline Cart & 7 \\
\hline Rickshaw & 847 \\
\hline Tractor & 63 \\
\hline Others & 135 \\
\hline
\end{tabular}

The vehicular damage calculated according to the crash severity came out to be pkr 210,492,324.

A total of 265 cases were recorded with the collision of vehicles to road furniture. The breakdown of the types of road furniture with respect to the number of crashes/collisions is as follows:

Table 4.8. Roadside Furniture data

\begin{tabular}{|c|c|c|}
\hline Type of Road Furniture & \# of Crash Cases & Cost Calculated in pkr \\
\hline Road Barrier / Kerbstones & 54 & 45,300 \\
\hline Bridge Parapet & 1 & 15000 \\
\hline Security Checkpoints & 2 & 10800 \\
\hline Electric Poles & 43 & $3,866,584$ \\
\hline Boundary Wall & 3 & 38400 \\
\hline Footpath & 161 & 374,900 \\
\hline Sign Board & 1 & 16,355 \\
\hline
\end{tabular}

Total cost for roadside furniture repair $=4,367,339$

\subsection{Administrative Cost}

Insurance Administrative Cost incurred in the year 2016 came out to be $\mathrm{pkr}$ 43,200,000. Total Police Administrative Cost for the Twin Cities came out to be pkr 26,039,736. For fuel adjustment factor of Emergency Medical Service Cost, it is assumed that each rescue station is responsible for any incident within $15 \mathrm{~km}$ radius of its premises. If a rescue vehicle covers $7.5 \mathrm{~km}$ in one liter of fuel (petrol), 2 liters of fuel is utilized by the vehicle in one travel from the department to the place of the accident, 2 is utilized to the hospital, and say 4 is utilized while coming back to the department. The overall fuel of 8 liters is assumed to be utilized for one case. Considering the price of fuel in the year 2016, total fuel cost came out to be pkr 4,482,289. For monetizing time for the Emergency Medical Service Cost, a time period was specified for each injury type on spot treatment as well as the time the patient is being carried to the nearest Medical center. The amount came out to be pkr 12,008,072. Hence, the total administrative cost incurred was pkr 85,730,725. 


\section{Conclusion}

Total costs of Road Traffic Accidents incurred in the year 2016 was pkr 2,183,306,768. The breakdown of the costs with respect to components along with their percent share is given below:

Table 4.9. Total cost components

\begin{tabular}{|c|c|c|}
\hline Type of Costs & Amount in pkr/- & Percent Share \\
\hline Medical & $93,898,640$ & 4.266521 \\
\hline Human & $473,584,345$ & 21.69115 \\
\hline Lost output & $1,316,000,000$ & 60.27554 \\
\hline Property Damage & $214,840,463$ & 9.840141 \\
\hline Administrative & $85,730,725$ & 3.926646 \\
\hline Total & $2,183,306,768$ & 100 \\
\hline
\end{tabular}

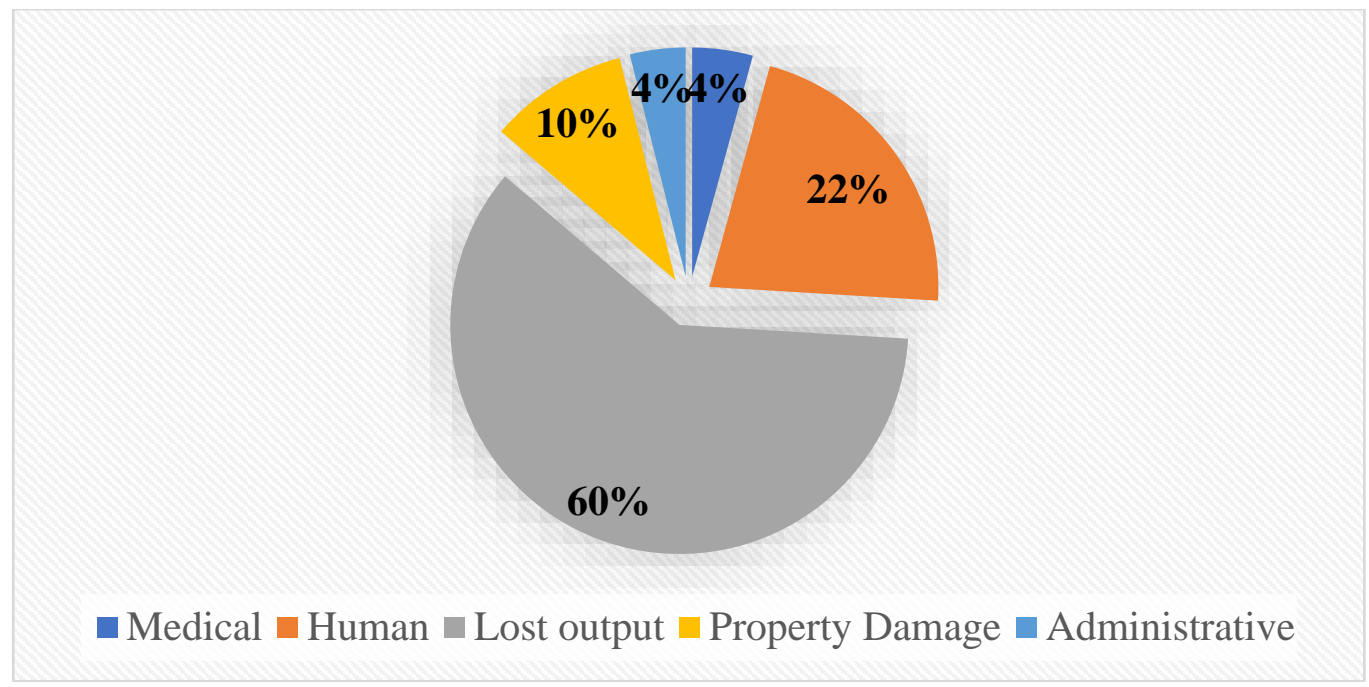

Figure 4.1. Cost Components

A loss output of about $60 \%$ and human life loss of $22 \%$ of the total cost indicates that a road traffic accident affects the individual productivity loss the most, which may be the result of temporary or permanent injury or fatality. It is because more than $50 \%$ of the total victims belonged to the productive age group as seen in the statistics. The recorded RTAs are responsible for costing pkr 2.18 billion in just the twin cities in the year 2016 to the state of Pakistan and $0.0074 \%$ of total GDP of Pakistan in the year 2016. It was noticed that in the year 2016, a total of 10187 accidents have been recorded in the twin cities. However, there must be many others that were unrecorded. This was mainly because of the less awareness of people or the amount of fatigue a victim must go through while having an accident recorded. Considerable measures need to be taken so as to control such huge damage to the economy of the state. Educating the road drivers should be the foremost priority of the state. Strict law enforcement needs to be ensured so as to avoid road crashes from 
happening. It was recommended that a proper database should be constructed for storing the data pertaining to Road Traffic Accident and these data should be properly managed at district national levels. This would ultimately result in accident management in all the rural areas of a district as well.

\section{References:}

1. Al-Masaeid, H. R., Al-Mashakbeh, A. A., \& Qudah, A. M. (1999). Economic costs of traffic accidents in Jordan. Accident Analysis \& Prevention, 31(4), 347-357.

2. Bishai David, et al. (2006). "National road casualties and economic development."Health Economics 15.1: 65-81.

3. Connelly, L. B., \& Supangan, R. (2006). The economic costs of road traffic crashes: Australia, states and territories. Accident Analysis \& Prevention, 38(6), 1087-1093.

4. De Leon, M. R. M., Cal, P. C., \& Sigua, R. G. (2005). Estimation of socio-economic cost of road accidents in Metro Manila. Journal of the Eastern Asia Society for Transportation Studies, 6, 3183-3198.

5. Downing, A. J., Baguley, C. J., \& Hills, B. L. (1991, September). Road safety in developing countries: an overview. In The nineteenth transport, highways and planning summer annual meeting, University of Sussex, Brighton.

6. Elvik, R. (2000). How much do road accidents cost the national economy?. Accident Analysis \& Prevention, 32(6), 849-851.

7. Jacobs, G. D., \& Sayer, I. (1983). "Road accidents in developing countries."Accident Analysis \& Prevention 15.5: 337-353.

8. Kopits, Elizabeth, \& Maureen Cropper (2005). "Traffic fatalities and economic growth." Accident analysis \& prevention 37.1: 169-178.

9. Luathep, P., \& Tanaboriboon, Y. (2005). Determination of economic losses due to road crashes in Thailand. Journal of the Eastern Asia Society for Transportation Studies, 6, 3413-3425.

10. Reddy, G. M., Negandhi, H., Singh, D., \& Singh, A. J. (2009). Extent and determinants of the cost of road traffic injuries in an Indian city. Indian journal of medical sciences, 63(12), 549-556.

11. Sahu, P. K. (2012). Social Loss Estimation Due To Road Accidents. World report on road traffic injury prevention (2004). http://www.who.int/violence_injury_prevention/publications/road_tra ffic/world_report/summary_en_rev.pdf 